Research Paper

\title{
Mapping the relationships between trail conditions and experiential elements of long-distance hiking
}

\author{
Brian A. Peterson ${ }^{a}$, Matthew T.J. Brownlee ${ }^{a, *}$, Jeffrey L. Marion ${ }^{\mathrm{b}, \mathrm{c}}$ \\ a Clemson University, United States \\ ${ }^{\mathrm{b}}$ U.S. Geological Society (USGS), United States \\ ${ }^{\mathrm{c}}$ Virginia Tech University, United States
}

\section{A R T I C L E I N F O}

\section{Keywords:}

Appalachian Trail

Long-distance hiking

Recreation suitability mapping

Trail conditions

Experiential impacts

\begin{abstract}
A B S T R A C T
Trail users that experience acceptable social and ecological conditions are more likely to act as trail stewards, exhibit proper trail etiquette, and use low-impact practices. However, the relationships between specific trail conditions and experiential elements of long-distance hiking are not well understood. Therefore, the purpose of this study was to identify how trail conditions influence particular elements of the long-distance hiking experience. The researchers used a mixed-methods approach involving semi-structured interviews $(n=17)$, quantitative questionnaires $(n=336)$, ecological measurements of trail conditions $(n=21-5 \mathrm{~km}$ sections), and modified Recreation Suitability Mapping (RSM) techniques to quantify the relationships between five trail conditions (trail incision, muddiness, rugosity, trail width, and gradient) and four experiential elements of longdistance hiking (level of challenge, perceived impact to musculoskeletal system, valuation of tread aesthetics, and ability to maintain an ideal hiking pace). Quantified values were weighted, analyzed, and mapped using SPSS 22.0 and ArcMap 10.2.2. Significant differences exist in the scores and distributions of ecological measures across all sections, indicating that trail conditions vary significantly across sampled trail sections. Although, long-distance hikers felt all four experiential elements were important, tread aesthetics was ranked by $50.2 \%$ of sampled hikers as the most important experiential element to the overall experience. The resulting information after applying the weights suggests what particular type of experience is likely for each trail section considering the presence of trail conditions.
\end{abstract}

\section{Introduction}

Recreational trail use has been increasing for decades (Outdoor Outdoor Outdoor Foundation, 2017). In 1995, the National Survey on Recreation and the Environment reported that outdoor recreation participation was growing faster than the population (Cordell, Lewis, \& McDonald, 1995), a trend that continues to this day (Outdoor Foundation, 2017). Specifically, in 2017, the Outdoor Foundation Recreation Participation Topline Report indicated that a record number of Americans participated in outdoor activities, including increased recreation on trails. With more people using trails, more ecological impacts are occurring, often resulting in undesirable trail conditions (Ballantyne \& Pickering, 2015; Hockett, Marion, \& Leung, 2017).

In response, trail managers continuously aim to design and maintain ecologically sustainable trails that feature conditions that users desire (Marion, 2016; Marion \& Wimpey, 2017). Land managers are charged with maintaining sustainable ecological and social conditions, and trails are resources that managers must protect (Monz, 2009). In turn, wellmanaged trails with desirable tread conditions positively influence the recreation experience, leading to satisfied users (Marion \& Leung, 2001).

The importance of sustainable trails with desirable tread conditions extends beyond user satisfaction (Dorwart, Moore, \& Leung, 2009) and contribute to appreciation of nature, support for outdoor environments, and enjoyment (Manning, 2011). More specifically, trail users who encounter desirable conditions may adopt low-impact practices and act as resource stewards (McFarlane, Boxall, \& Watson, 1998). Therefore, providing opportunities for high-quality experiences based on desirable conditions is important to most managers (IVUMC (Interagency Visitor Use Management Council), 2016).

One important group of trail users is long-distance hikers, who trek 500 miles or more during a single outing (Anderson et al., 2009). Long-

\footnotetext{
* Corresponding author at: Parks and Conservation Area Management, Department of Parks, Recreation, and Tourism Management, Clemson University, Lehotsky Hall 298, United States.

E-mail address: mbrownl@clemson.edu (M.T.J. Brownlee).
} 
distance hikers are a heralded group that often serve as role models for other trail users (Littlefield \& Siudzinski, 2012). If long-distance hikers encounter desirable trail conditions, they are likely to develop an affinity for the trail and practice proper trail ethics (Williams, Patterson, Roggenbuck, \& Watson, 1992). Such high regard for the trail may influence other types of hikers (e.g., day hikers) who look to long-distance hikers as examples (Ptasznik, 2015). Additionally, research indicates that the quality of outdoor experiences is dependent in part on the environmental conditions of trail treads and corridors (Leung \& Marion, 2000). Therefore, understanding the relationships between trail conditions and the quality of long-distance hiking experiences is important to the larger hiking and management community.

Understanding where specific trail conditions contribute to high quality long-distance hiking experiences can be difficult to identify because social data (e. g., preferences for trail conditions) are often not geographically located (Beeco, Hallo, \& Brownlee, 2014). Recreation Suitability Mapping (RSM) is a technique that makes it possible to identify and display the relationships between social preferences, ecological conditions, and landscape features (see Beeco et al., 2014). Investigating these spatial relationships is important because ecological and social preferences should be investigated in tandem to understand reciprocal associations (Manning, Leung, \& Budruk, 2005). Understanding this reciprocity is critical to advancing the sustainability of long-distance hiking trails (Marion \& Wimpey, 2017).

However, the reciprocity between trail conditions and experiential elements of long-distance hiking is not well understood, nor has it been mapped across multiple sections of a hiking trail using RSM techniques. Understanding how trail conditions influence long-distance hiking experiences at a specific location could provide managers with information for trail design and maintenance. Mapping the relationships between trail conditions and experiential elements of long-distance hiking may also provide managers with concise information that they can access more easily and efficiently than other approaches. Therefore, the purpose of this study was twofold: 1 ) to examine which trail conditions influence particular experiential elements of long-distance hiking, and to what degree; and 2) to index, map, and analyze these relationships using modified RSM techniques.

\section{Literature review}

The literature review has three sections and provides background on trail conditions, experiential elements of long-distance hiking, and RSM techniques. The researchers used a general scoping approach (see Arksey \& O'Malley, 2005) employing Boolean strings to search research databases for peer-reviewed English-language publications (PsychInfo, Scopus, LeisureTourism, Google Scholar, and Web of Science) and doctoral dissertations and graduate thesis (ProQuest, Ebsco). Additionally, the research team used subject area journals in leisure studies (e.g., Leisure Sciences), ecological management (Journal of Environmental Management), outdoor recreation (e.g., Journal of Outdoor Recreation and Tourism), nature-based tourism (e.g., Journal of Ecotourism), and protected area scholarship (e.g., Society and Natural Resources) for manual searching.

\subsection{Trail conditions}

The trail conditions included in this study were trail incision (depth), muddiness (wet soils), rugosity (roughness), width, and gradient (slope) (Marion, Leung, Eagleston, \& Burroughs, 2016) (Fig. 1). The researchers chose these conditions based on the literature, and because these conditions reflect common trail impacts and/or hiking difficulty on long-distance trails. Furthermore, hikers are generally aware of these conditions without the need for additional education and explanation. In the following section, these five trail conditions are defined, their measurement is highlighted, and their potential influence on the hiking experience is described.
Trail incision is the depth of the tread in relation to the sides of the trail (Marion \& Wimpey, 2017). Incision correlates with soil loss caused by wind and water erosion, compaction, and soil displacement (Olive \& Marion, 2009). Significant soil loss can cause hikers to wander laterally, widening the trail, causing greater vegetation and soil loss over time (Wimpey \& Marion, 2010).

Muddiness occurs on flat sections of trail that retain water and where terrain lacks drainage or permeability (Marion \& Leung, 2001; Marion et al., 2016). Muddiness can be measured by identifying the lineal extent of the muddy area (Moore, Leung, Matisoff, Dorwart, \& Parker, 2012). Muddiness may cause hikers to circumnavigate muddy areas, resulting in trail widening and vegetative trampling (Marion et al., 2016). Muddiness can also increase travel difficulty, reducing hiking speed and stability.

Rugosity is the roughness of the trail, generally caused by soil loss, and exposed rocks and roots in the tread (Marion \& Wimpey, 2017; Wimpey \& Marion, 2010). Rugosity often causes hikers to seek smoother terrain, often parallel to but off of the official tread (Wimpey \& Marion, 2010). Tread rugosity can slow and distract hikers because they must be cognizant of foot placement to avoid rocks and roots that increase the chance of tripping and falling (Moore et al., 2012).

Trail width is the gap in vegetation growth where the trail resides and is central to supporting trail traffic (Marion et al., 2016). Trail width can be measured with a standard tape measure extended across the trail tread from boundaries defined by visually obvious trampling disturbance (Wimpey \& Marion, 2010). Excessive trail width means there is a larger areal extent of impact to vegetation, organic litter, and soil, often decreasing the aesthetics of the trail (Wimpey \& Marion, 2010).

Trail gradient is the slope of the trail and is typically measured as rise/run (Marion \& Wimpey, 2017). Researchers and managers generally use a clinometer to measure trail gradient (Sutherland, Bussen, Plondke, Evans, \& Ziegler, 2001). As trails become steeper, they typically experience greater erosion, due to the increasing velocity of water runoff (Olive \& Marion, 2009). Most hikers indicate that trails with steep grades are generally more challenging (Zealand, 2007).

These five trail conditions, except trail gradient, are direct impacts born from recreational use (Lynn \& Brown, 2003) (Fig. 1). The relative prevalence of these five trail conditions likely affect the quality of hiking experiences (Lynn \& Brown, 2003), potentially more than other factors, such as crowding (Dorwart et al., 2009).

\subsection{Experiential elements of long-distance hiking}

Informed by the literature, the researchers selected four experiential elements of long-distance hiking: level of challenge, perceived impact to the musculoskeletal system, valuation of tread aesthetics, and hiking pace. The researchers selected these four elements for inclusion in this study because they a) are common variables of interest in park visitation and outdoor recreation studies (e.g., Manning, 2011), b) have the potential to influence the quality of a hiking experience, c) are often elements addressed in guide books and online forums by veteran hikers and hiking enthusiasts (e.g., Appalachian Trail Conservancy, 2018; Mueser, 1998), and d) emerged as important elements of long-distance hiking during qualitative interviews conducted in this study.

According to Mueser (1998), challenge is testing one's physical ability and self-esteem, and is the primary reason for long-distance hiking. Establishing predetermined distance goals is part of the process that hikers use to challenge themselves (Kil, Stein, \& Holland, 2014). The challenge of a long-distance hike is unmatched and unusual, and according to den Breejen (2007), challenge is integral to the hiking experience. However, hikers may perceive level of challenge differently depending on personality characteristics and previous experiences (Zealand, 2007). Level of challenge can also be different when comparing numerous trail sections, as is the case when comparing diverse trail sections that contain varying terrain and trail conditions 


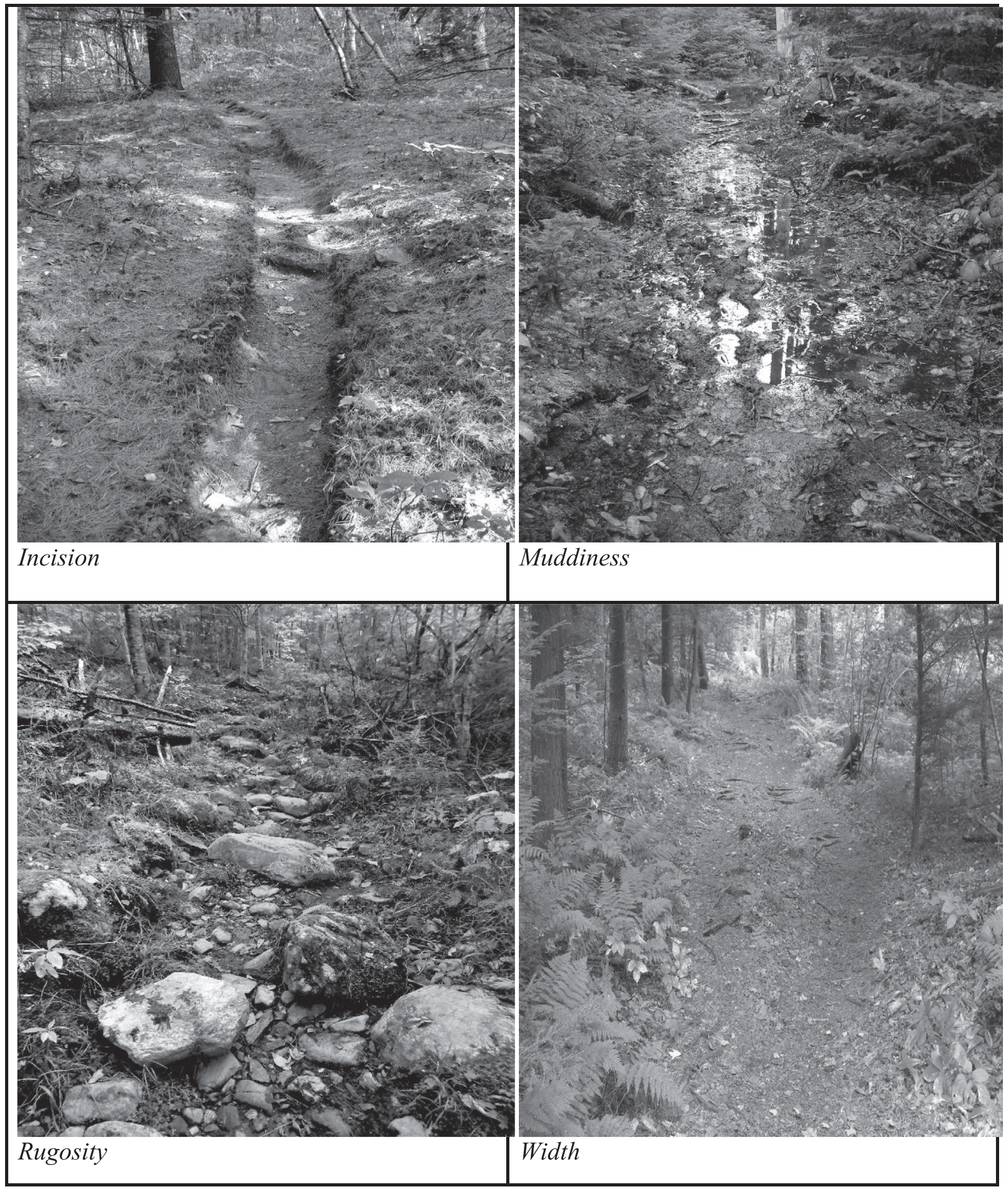

Fig. 1. Trail Conditions.

(Appalachian Trail Conservancy, 2018).

Impact to the musculoskeletal system is paramount to the hiking experience, because injuries can slow or stop a hike. Injuries to the musculoskeletal system include fractures, joint pain, sprains, and strains (Boulware, 2004). Anderson et al. (2009) states that "musculoskeletal injuries represent a significant source of morbidity among long-distance hikers" (p. 252). Long-distance hikers are high risk for impacts to the musculoskeletal system due to carrying substantial loads and provisions in their backpacks (Knight \& Caldwell, 2000). Previous research has demonstrated that increased backpack loads produce greater knee and trunk flexion, which is often exacerbated by steep downhills or high rugosity (Han, Harman, Frykman, Johnson, \& Rosenstein, 1992).

Valuation of trail aesthetics is an important element of the hiking experience because the trail tread is always visually present. For the purpose of this study, the researchers evaluated preferences for 'tread aesthetics', not the overall aesthetics that surround the trail corridor, which may include vistas, amount and type of vegetation, and color variation. Researchers have found that degradation of ecological conditions in recreation settings (e.g., campsites and hiking trails) may decrease the experiential quality of recreational activities (Price, Blacketer, \& Brownlee, 2018). Visually offensive tread conditions can 


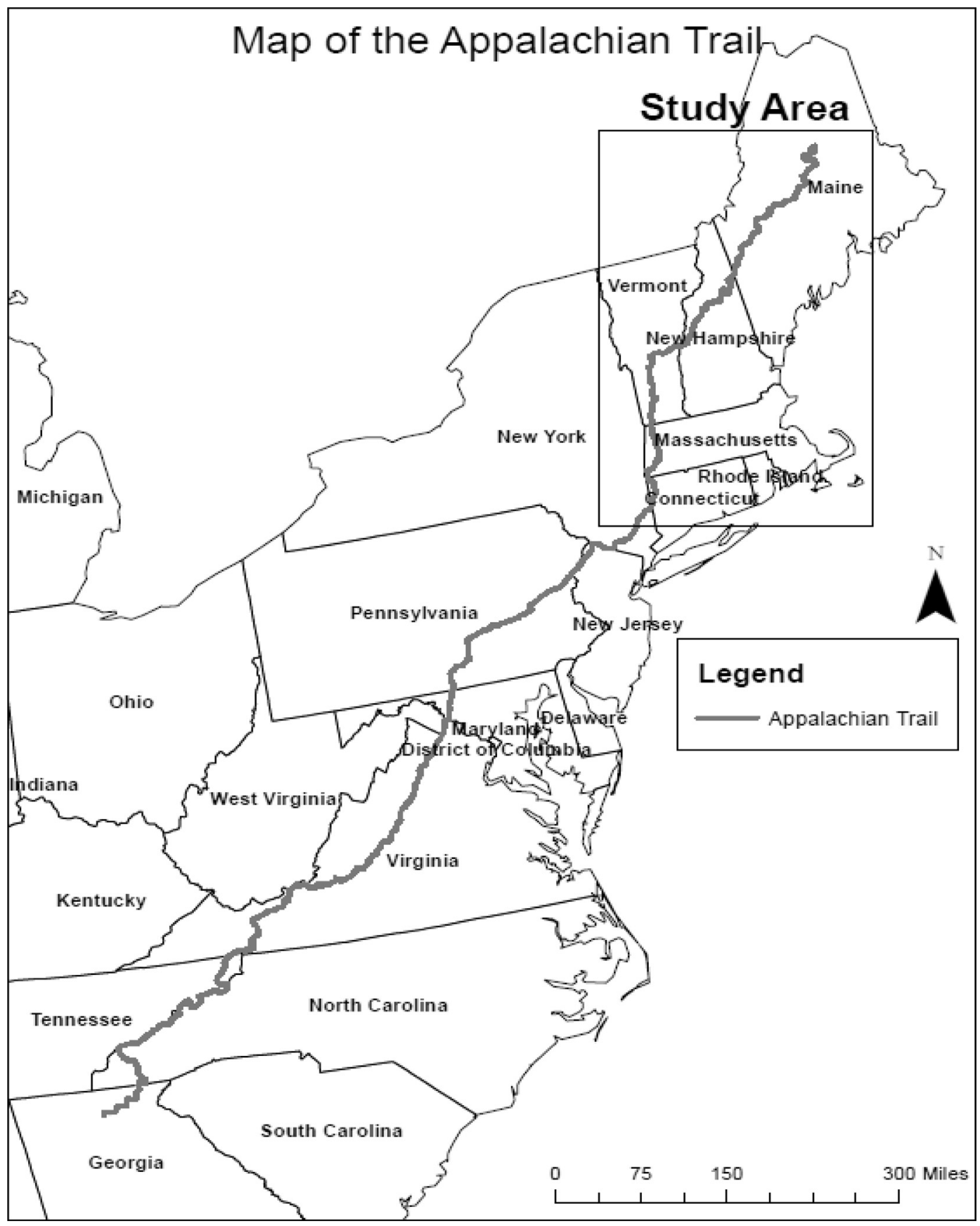

Fig. 2. Map of the Appalachian Trail and study area.

lower the functional value of the trail and thus influence the experience (Marion \& Leung, 2001).

Finally, maintaining an ideal hiking pace is important to the completion of long-distance hikes. The completion date of the hike is important to avoid undesirable seasonal weather, particularly in northern sections of long-distance hiking trails. Degraded conditions typically compromise a hiker's pace, and consequently the hiker may not complete the hike or reach resupply points within the allotted times (Saunders, Laing, \& Weiler, 2013).

\subsection{Spatial mapping}

Recreation Suitability Mapping (RSM) is a GIS approach that models landscape features to identify areas most suitable for specific recreation activities (Kliskey, 2000). RSM quantifies areas of recreational worth by identifying and weighting social preferences for conditions that can be mapped (Kliskey, 2000). For example, a bird watcher may prefer a landscape with specific vegetation and a certain percent of tree cover, while a landscape photographer may prefer open vistas. Such preferences for varying conditions can be mapped and displayed to inform decisions regarding recreation activity zoning and to assess the suitability of an area for specific activities. Some examples of resource conditions mapped by researchers and managers are topography, soil types, vegetation type and density, proximity to water, and wildlife habitat (Beeco et al., 2014). Ultimately, RSM techniques provide a greater understanding of resource and terrain conditions and how resource conditions may affect recreational experiences (Beeco, Hallo, \& Giumetti, 2013).

Relationships between landscape features, trail conditions, resource attributes, and experiential elements of the recreation experience can 
be indexed, weighted, and spatially embedded into GIS layers using procedures outlined by Beeco et al. (2014). Generally, RSM methods include four primary steps: 1) identify and map terrain and ecological conditions deemed important to the recreation activities of interest; 2) identify social preferences for these conditions using quantitative questionnaires administered to representative samples of the activity groups of interest; 3 ) scale and weight the relationships between ecological conditions and social preferences; and 4) display and analyze the resulting relationships using GIS techniques (Beeco et al., 2014). This four-step process produces maps that clearly identify the relationships between resource conditions and overall experiential values. However, researchers have traditionally employed RSM at the landscape scale and not along a restricted recreation corridor such as a trail.

\section{Research questions}

The following research questions guided the investigation of the relationships between trail conditions and experiential elements of long-distance hiking. The aim of these research questions was to a) to examine which trail conditions influence particular experiential elements of long-distance hiking, and to what degree; and b) to index, map, and analyze these relationships using modified RSM techniques.

1. Which trail conditions influence particular experiential elements of long-distance hiking, and to what degree?

2. Which sampled trail sections contain conditions that contribute to high or low-quality hiking experiences?

3. What are efficient methods for indexing, weighting, and mapping the relationships between trail conditions and experiential elements of long-distance hiking?

4. How may spatially mapping the relationships between trail conditions and experiential elements of long-distance hiking inform management decisions regarding trail improvement and maintenance?

\section{Description of research location}

The Appalachian Trail (AT) is located in the eastern United States, extending from Springer Mountain in Georgia to Mount Katahdin in Maine (2200 miles), and passing through 14 states (Appalachian Trail Conservancy, 2018) (Fig. 2). The National Park Service (NPS) manages the AT in partnership with the Appalachian Trail Conservancy (ATC) and 31 trail clubs responsible for trail management and maintenance (Appalachian Trail Conservancy, 2018). While approximately 2-3 million people take day-hiking or backpacking trips on the AT annually, in 2015 about 3466 attempted a single-year "thru-hike," with a completion rate of only 25\% (Appalachian Trail Conservancy, 2018). Longdistance hikers consider the northern third of the AT to be the most environmentally diverse and physically challenging due to steeper terrain and the preponderance of rocks, muddiness, and roots (Appalachian Trail Conservancy, 2018).

The northern third of the AT, spanning 734 miles from the New York-Connecticut border to the northern terminus at Mount Katahdin in Maine, was the study area for this research due to the diverse steep and challenging terrain. The Connecticut section of the AT is 51.6 miles, with elevation ranging from 260 to $2316 \mathrm{ft}$ (Appalachian Trail Conservancy, 2018), while the AT section in Massachusetts is 90.2 miles, with elevation ranging from 650 to $3491 \mathrm{ft}$. In Vermont the AT passes through rugged terrain along the crest of the Green Mountains (149.8 miles long, with elevation ranging from 400 to $4010 \mathrm{ft}$ ). The New Hampshire section of the AT passes through the White Mountains, which features the most miles above tree line compared to any other AT state (Appalachian Trail Conservancy, 2018). This section is 160.9 miles, with elevation ranging from 400 to $6288 \mathrm{ft}$. The AT in Maine is 281.4 miles, with elevation ranging from 490 to $5267 \mathrm{ft}$.

\section{Methods}

As a guiding framework, the researchers selected an exploratory mixed methodology (Clark \& Creswell, 2011) with three connected phases. In Phase 1, the researchers conducted interviews with AT longdistance hikers to identify important experiential elements that aligned with the literature. In Phase 2, the researchers developed, piloted, and administered a questionnaire for AT long-distance hikers. Also, in Phase 2 , the researchers measured and assessed ecological trail conditions on the Northern AT. In Phase 3, the researchers indexed, weighted, analyzed, and displayed the relationships between trail conditions and experiential elements of long-distance hiking using ArcMap software. This sequential process was selected because a) not all quantitative measures or instruments for the phenomenon under investigation were available, b) some variables were unknown, and c) due to the novelty of the investigation, numerous frameworks or theories were applicable (Clark \& Creswell, 2011).

\subsection{Phase 1 - Initial interviews}

The researchers conducted semi-structured phone interviews with long-distance AT hikers using a modified Seidman (2013, p.21) approach during February of $2015\left(n=17 ; M_{\text {minutes }}=45\right)$. Interviewees had hiked at least 500 miles during a single outing, including thruhiking the AT for a subset of the respondents. The researchers used nonprobability convenience sampling to initially locate interview participants and used snowball sampling to identify subsequent participants. The sample consisted of 13 males and four females ranging from young adults to seniors. The researchers audio-recorded the interviews and used standard coding procedures outlined by Saldaña (2012) to identify and verify the most important experiential elements of longdistance hiking that aligned with the literature. Similar to the prevailing literature, the interviews revealed that challenge, perceived impact to the musculoskeletal system, trail tread aesthetics, and hiking pace were important experiential elements for AT long-distance hikers.

\subsection{Phase 2 - Instrument Development and data collection}

Using Phase 1 results and relevant literature, the researchers developed measurement items that captured long-distance hikers' preferences for trail conditions and experiential elements of long-distance hiking. Following procedures outlined by Beeco et al. (2014), the researchers used a) nine-point Likert scales to assess the preference of trail conditions for each experiential element of long-distance hiking ( $1=$ do not prefer; $9=$ highly prefer), b) rank order questions to identify the trail condition most influential for each experiential element, c) nine-point Likert scales that captured the importance of each experiential element $(1=$ not important at all; $9=$ extremely important), and d) a rank order question assessing how important each experiential element was to the overall AT experience. In addition to these measures, the researchers adapted previously validated items to measure a) hikers' Experience Use History, or the degree of previous hiking experience (Schreyer, Lime, \& Williams, 1984), and b) standard demographics (U.S. Census Bureau, 2015). The researchers combined these measures into a five-page, paper-based, anonymous questionnaire.

The researchers used photographs depicting trail conditions as part of the questionnaires to help respondents understand and visualize the trail conditions central to this study: trail incision, muddiness, rugosity, width, and gradient. Refer to Section 2.1 Trail Conditions, for descriptions and justification in using these trail condition indicators. The researchers used photographs because visual methods more effectively depict varying resource conditions than narrative descriptions (Manning \& Freimund, 2004). Experts $(n=3)$ reviewed the final selected photos ( $n=6$; one for each trail condition) and the questionnaire for content validity, sequencing, and item clarity. In the final step, the 


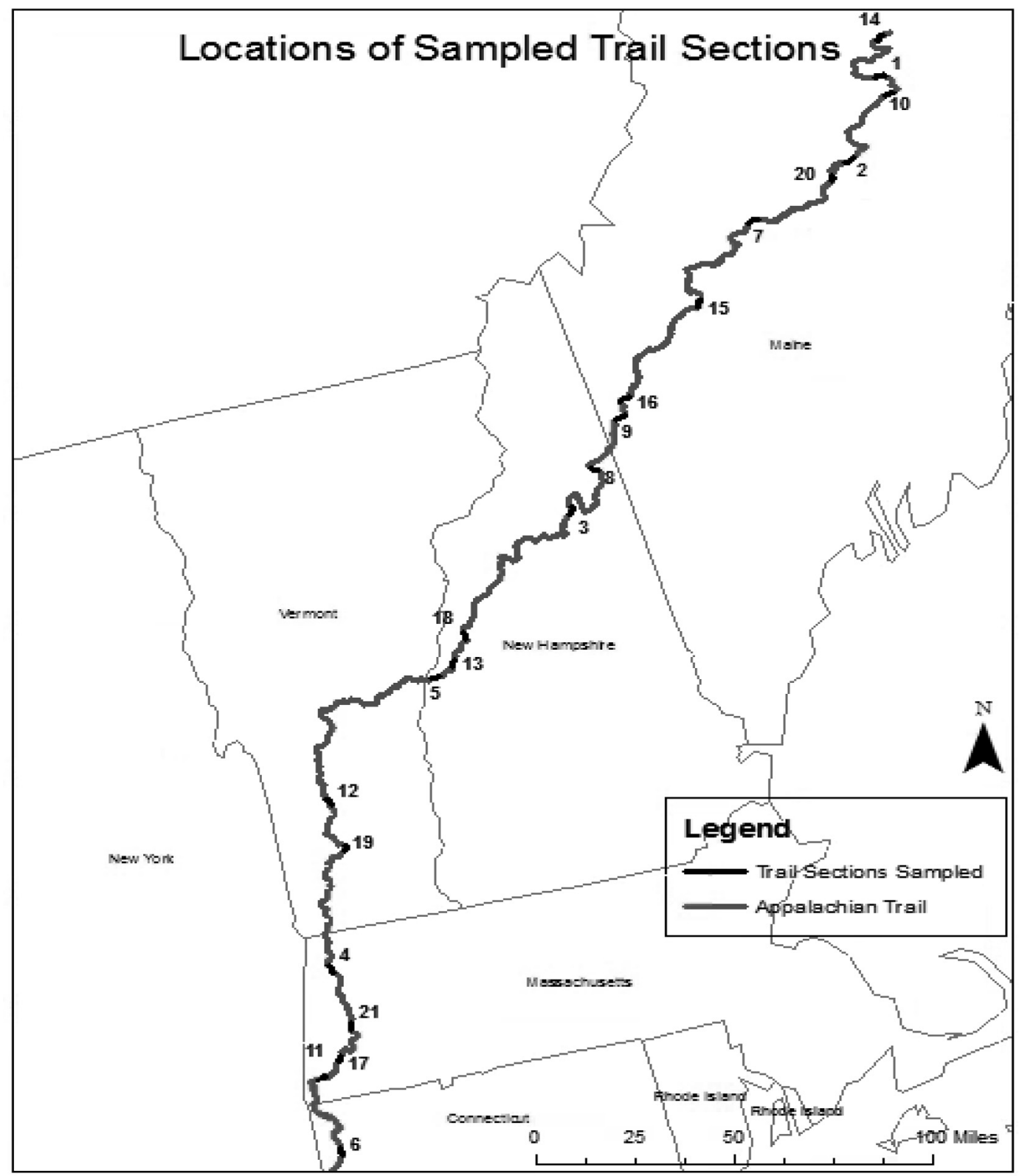

Fig. 3. Map of Appalachian centerline in green and the location of the 21 sections in red; 1 section in Connecticut, 4 in Massachusetts, 2 in Vermont, 5 in New Hampshire, and 9 in Maine. (For interpretation of the references to color in this figure legend, the reader is referred to the web version of this article.)

researchers conducted a pilot study with hikers $(n=17)$ to assess the overall clarity of the questionnaire and congruency with photographs.

The researchers administered the questionnaire using systematic random probability sampling (Vaske, 2008) at the Trail Days Festival in Damascus, Virginia in May 2015. This sampling location was deemed ideal because Trail Days is a) is focused on the AT, b) attended by a large number of long-distance hikers, c) popular with past and present long-distance AT hikers, and d) is the largest annual gathering of AT long-distance hikers in the world (Trails Days, 2016). The researchers administered questionnaires to hikers who a) had hiked 500 AT miles or more in a single outing, or b) were currently hiking the AT with the intention of hiking 500 miles or more. Since capturing high variability in survey responses was critical to this study, the researchers selected trail days as the social data sampling location because a diverse group of long-distance hikers were present in one location. Such diversity and resulting variability in survey responses may not have been possible using spatially confined sampling techniques at a small number of AT trailheads, trail towns, or AT shelters.
Following the questionnaire administration, the researchers assessed trail conditions for 21, 5-km sections on the Northern AT (Fig. 3). Similar to the social data, the researchers selected the Northern AT to ensure high variability in measured trail conditions because the northern third of the AT is the most environmentally diverse with abundance of varying terrain (Appalachian Trail Conservancy, 2018). Ultimately, sampling a diverse group of long-distance hikers at Trail Days and sampling a trail section with high variability in trail conditions ensured adequate variance for statistical analysis. The researchers selected trail sections using the Generalized Random Tessellation Stratified approach (GRTS), which is a spatially balanced sampling approach with a true probability design dependent on location (Lister \& Scott, 2009). Within each section, GRTS was used to identify 50 transect points for trail condition assessments, which were field located using a handheld Garmin 64 GPS unit.

At each transect point $(\mathrm{N}=1050)$, the researchers assessed a) maximum trail incision following procedures outlined by Marion, Leung, and Nepal (2006), b) muddiness using the percent of each trail 
Table 1

Average trail conditions in each section.

\begin{tabular}{|c|c|c|c|c|c|c|}
\hline Section ID & Incision (mm) & Muddiness (\%) & Width (mm) & Rugosity $\left(\mathrm{mm}^{2}\right)$ & Uphill (ft) & Downhill (ft) \\
\hline $6-\mathrm{CT}$ & 88.46 & 0 & 869.94 & 1625.30 & 1193 & 1134 \\
\hline 11 - MA & 35.67 & 0 & 878.37 & 462.26 & 344 & 350 \\
\hline 17 - MA & 75.39 & 0 & 375.00 & 1033.27 & 912 & 780 \\
\hline 21 - MA & 68.40 & 0 & 882.08 & 1198.27 & 563 & 534 \\
\hline 4 - MA & 59.14 & 2.4 & 548.84 & 906.27 & 1594 & 115 \\
\hline $19-\mathrm{VT}$ & 63.62 & 0 & 604.17 & 827.13 & 1199 & 867 \\
\hline $12-\mathrm{VT}$ & 69.24 & 4.69 & 654.86 & 975.31 & 338 & 1114 \\
\hline $5-\mathrm{NH}$ & 63.58 & 3.85 & 706.79 & 749.96 & 715 & 836 \\
\hline $13-\mathrm{NH}$ & 73.83 & 4.69 & 743.78 & 1561.91 & 389 & 1552 \\
\hline $18-\mathrm{NH}$ & 59.82 & 3.98 & 616.23 & 806.52 & 458 & 1557 \\
\hline $3-\mathrm{NH}$ & 161.15 & 0 & 1451.67 & 3704.52 & 1430 & 1001 \\
\hline $8-\mathrm{NH}$ & 79.93 & 0.91 & 1083.32 & 1198.51 & 1942 & 192 \\
\hline $9-\mathrm{ME}$ & 164.59 & 3.88 & 999.49 & 3771.48 & 2285 & 466 \\
\hline $16-\mathrm{ME}$ & 73.52 & 2.95 & 672.43 & 1150.35 & 1505 & 377 \\
\hline $15-\mathrm{ME}$ & 134.57 & 1.74 & 720.98 & 16143.18 & 1108 & 625 \\
\hline $7-\mathrm{ME}$ & 54.62 & 5.00 & 742.60 & 576.70 & 614 & 183 \\
\hline $20-\mathrm{ME}$ & 62.62 & 3.20 & 786.44 & 817.68 & 872 & 956 \\
\hline $2-\mathrm{ME}$ & 64.10 & 6.50 & 747.10 & 632.19 & 890 & 876 \\
\hline $10-\mathrm{ME}$ & 53.00 & 2.17 & 980.63 & 404.97 & 337 & 534 \\
\hline $1-\mathrm{ME}$ & 44.77 & 1.04 & 602.92 & 471.86 & 681 & 546 \\
\hline $14-\mathrm{ME}$ & 28.46 & 0 & 622.89 & 216.81 & 1639 & 225 \\
\hline F-Value & $5.48^{* k * *}$ & $9.64^{* * * * *}$ & $1.74^{*}$ & $2.04^{* * * *}$ & $\chi^{2}=220^{* * * k}$ & $\chi^{2}=119^{* * * *}$ \\
\hline
\end{tabular}

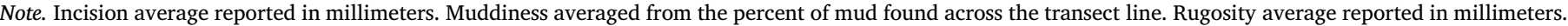
Uphill and downhill reported as the total uphill and downhill for each section in feet traveling north on the AT. ${ }^{*} p<0.05 ;{ }^{* * * *} p<0.001$.

transect containing mud (Marion et al., 2016), c) rugosity by calculating the variance of cross-sectional verticality across the trail (Wimpey \& Marion, 2010), and d) trail width (Wimpey \& Marion, 2010). The researchers used Google Earth to identify the amount of uphill and downhill in each of the 21 sections in the northbound direction, because the northbound direction is the most popular direction for AT long-distance hikers (Appalachian Trail Conservancy, 2018).

\subsection{Phase 3 - Indexing variables and mapping}

The researchers used two steps in the social-spatial mapping process: 1) weighting variables in SPSS 22.0 and EQS 6.1, and 2) mapping and analyzing the relationships in ArcMap 10.2.2. Specifically, the researchers adapted and augmented weighting procedures outlined by Beeco et al. (2014) and Kliskey (2000). Ultimately, each trail section received scores for specific trail conditions, each experiential element of long-distance hiking, and the overall experience using the procedures described below.

\subsubsection{Weighting variables}

The researchers developed two variable weights adapting previous weighting procedures described by Beeco et al. (2014) and Kliskey (2000). The first weight $\left(\mathrm{W}_{1}\right)$ captured the contribution of hikers' preferences for each trail condition (incision, muddiness, rugosity, width, uphill, and downhill) relative to each experiential element of long-distance hiking (level of challenge, perceived impact to musculoskeletal system, valuation of tread aesthetics, and ability to maintain an ideal hiking pace). For example, a hiker may have preferred a rough trail over a wide trail to experience challenge or a wide trail more than an incised trail to maintain an ideal hiking pace. The second weight $\left(\mathrm{W}_{2}\right)$ ranked the contribution of hikers' preference for each experiential element of long-distance hiking relative to the overall hiking experience. For example, a hiker may have preferred challenge more than tread aesthetics when determining the quality of their overall hiking experience or prefer an ideal hiking pace more than experiencing a challenge. Overall, these weighting procedures produced scores that represented each trail section's capacity to provide a 'preferable overall experience' relative to desirable trail conditions that contributed to challenge, aesthetics, pace, and limited impact to musculoskeletal system. Please see Peterson (2016) for specific weighting equations used in this study.

\subsubsection{Mapping}

The researchers imported these weights into ArcMap 10.2.2 along with the locations of the 21 sections sampled and the AT centerline. Next, trail section scores were then classified using Jenks Natural Breaks (Jenks, 1963) and subsequently color coded, which depicted a color for each trail section determined by weight. The final map included five weighted layers for each trail section, comprised of a layer for each of the four experiential elements of long-distance hiking, and one aggregate layer for the overall experience scores.

\section{Results}

\subsection{Description of the sample}

During sampling, 336 long-distance hikers completed the questionnaire (response rate $=70 \% ; 5.26 \% \mathrm{CI}$ ). This sample comprises approximately $9.7 \%$ of all A.T. thru-hikers (data is unavailable on sectionhiker numbers). The researchers used standard calculations for leverage, kurtosis, and skewness to identify statistical outliers and to verify univariate and multivariate normality of the data (Tabachnick \& Fidell, 2007). One case was excluded from subsequent analysis due to extreme violations of multivariate normality identified using $\chi^{2}$ bounds derived from the Mahalanobis Distance Equation (Tabachnick \& Fidell, 2007).

The majority of respondents reported residing in the United States (97.0\%), specifically within the Eastern Time Zone (73.0\%), with the highest representation coming from Virginia and North Carolina (8.0\% respectively). The average age of respondents was 32 years. The majority of the sample was male $(71.3 \%)$ with limited differences in respect to race ( $90.5 \%$ self-identified as white). The sample had varying educational backgrounds: $28 \%$ received some college, and $38.4 \%$ reported receiving a 4-year college degree. Over one-third $(38.7 \%)$ reported making less than $\$ 24,999$ in household income annually. On average, the sample reported hiking 618 miles in the last 12 months, and 2441 miles during their lifetime. 


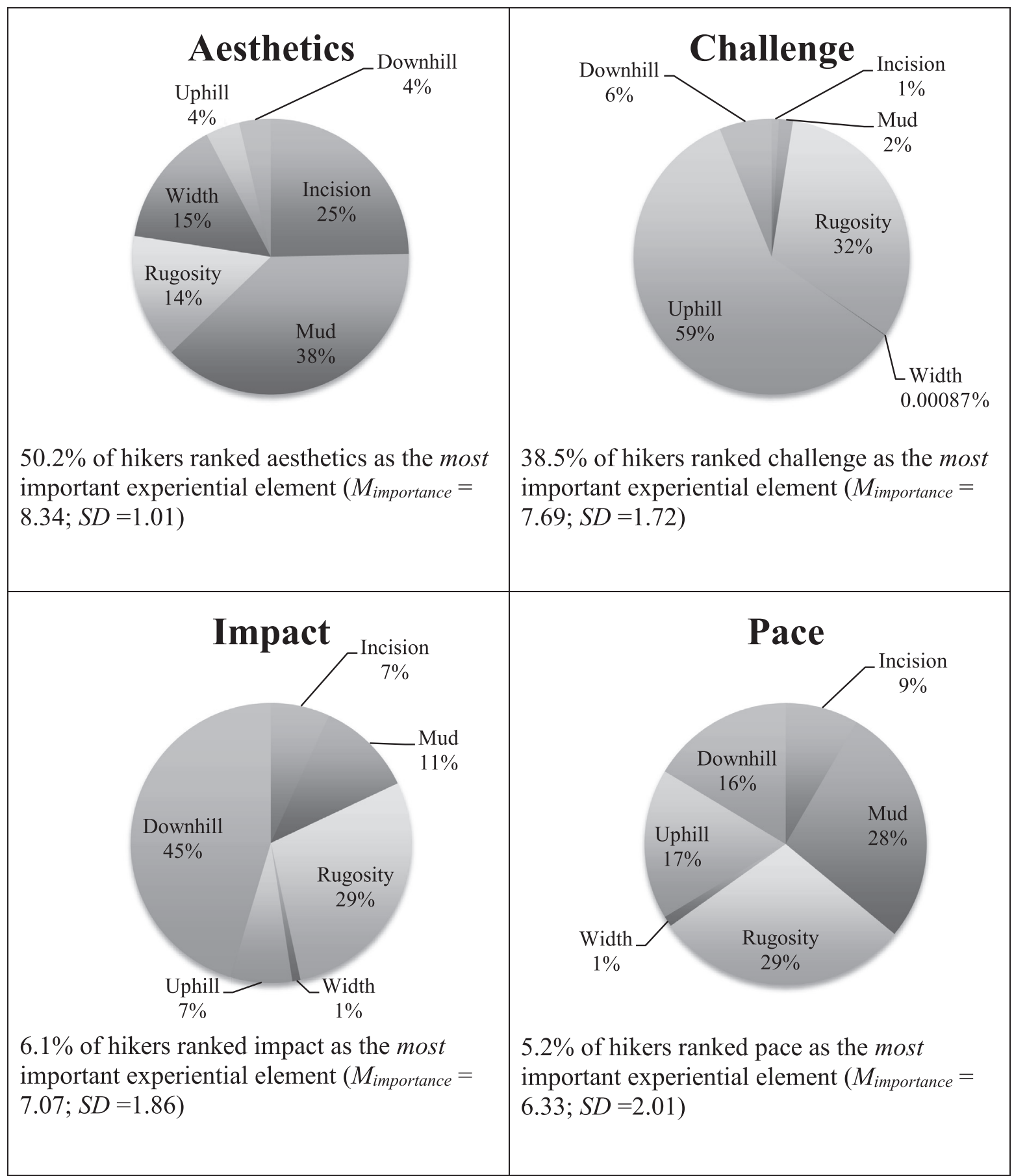

Fig. 4. The influence of each trail condition to each experiential element of long-distance hiking. $\mathrm{M}_{\text {importance }}$ derived from a 9-point Likert scale anchored with $1=$ 'not important at all' and $9=$ 'extremely important', in respect to the importance of the experiential element to the overall long-distance hiking experience. $\mathrm{M}_{\mathrm{importance}}$ is significantly different across all four experiential elements $\left(\mathrm{F}=5.61^{* * * *}\right)$. The influence of each trail condition differs significantly within each experimental element $\left(\chi^{2}>106.63^{* * * *}\right){ }^{* * * *} \mathrm{p}<0.001$.

\subsection{Trail conditions}

One way ANOVA results and chi-square distributions were evaluated to identify the variability of trail conditions across trail sections (Table 1). Significant differences exist in the scores and distributions across all sections $(p<0.05)$, indicating that trail conditions vary significantly across sampled trail sections.

\subsection{Results of relationships between variables}

Results addressing Research Question 1 (Which trail conditions influence particular experiential elements of long-distance hiking, and to what degree?) are displayed in Fig. 4. Although, long-distance hikers felt all four experiential elements were important ( $M_{\text {importance }}$ ranged from 6.33 to 8.34 out of 9), sampled hikers ranked tread aesthetics as being the most important experiential element. The average importance rating was significantly different across all four experiential elements $(F=5.61 ; p<0.001)$. Additionally, the influence of each trail 
condition differs significantly within each experimental element $\left(\chi^{2}>106.63 ; p<0.001\right)$. This suggests that trail experiences that are important to long-distance hikers vary by level of importance and that each experimental element is influenced by its own unique combination of trail conditions.

Tread aesthetics was ranked by $50.2 \%$ of long-distance hikers as the most important experiential element to the overall experience. Tread aesthetics displayed a high mean importance ( 8.34 out of $9 ; \pm 1.01$ ), suggesting that long-distance hikers agree that tread aesthetics was highly important. Muddiness (38\% degree of influence) and incision (25\% degree of influence) were reported by long-distance hikers as the trail conditions that negatively influenced tread aesthetics the most.

Long-distance hikers found level of challenge important to the overall experience as well. Challenge was ranked by $38.5 \%$ of longdistance hikers as being the most important experiential element to the overall experience and received a mean importance score of 7.69 $( \pm 1.72)$. Different from tread aesthetics, uphill grade $(59 \%)$ and rugosity (32\%) were reported by long-distance hikers as the trail conditions that positively contributed to challenge the most. Conversely, and logically, width $(<1 \%)$ had the smallest influence on challenge.

Perceived impact to the musculoskeletal system was shown to have little influence on the overall experience; only $6.1 \%$ of long-distance hikers ranked impact as the most important experiential element to the overall experience, but most agreed that impact held some importance $\left(M_{\text {importance }}=7.07\right.$; s.d. $\left.=1.86\right)$. Regarding the trail conditions that influenced impact the most, long-distance hikers reported that downhill $(45 \%)$ and rugosity (29\%) were quite influential.

The ability to maintain an ideal hiking pace was reported to be the least influential experiential element to the overall experience. Only $5.2 \%$ of long-distance hikers ranked pace as being the most important experiential element and pace received a moderate mean importance score $\left(\mathrm{M}_{\text {importance }}=6.33\right.$; s.d. $\left.=2.01\right)$. The larger standard deviation for pace suggests high variation and potential disagreement about the importance of pace. Rugosity (29\%) and muddiness (28\%) were reported as the top two trail conditions that influenced pace.

\subsection{Section scores for experiential elements and overall experience}

Results displayed in Table 2 address Research Question 2 (Which

Table 2

Section scores for each experiential element of long-distance hiking and overall hiking experience.

\begin{tabular}{llllll}
\hline Section ID & Challenge & Aesthetics & Pace & Impact & Overall \\
\hline $6-\mathrm{CT}$ & 4.44 & 4.25 & 3.89 & 3.26 & 4.41 \\
$11-\mathrm{MA}$ & $2.74^{\mathrm{b}}$ & 5.29 & $5.61^{\mathrm{a}}$ & 5.35 & 5.11 \\
$17-\mathrm{MA}$ & 3.77 & 5.12 & 4.65 & 4.22 & 5.19 \\
$21-\mathrm{MA}$ & 3.35 & 4.71 & 4.89 & 4.59 & 4.62 \\
$4-\mathrm{MA}$ & 4.49 & 4.47 & 4.32 & 5.06 & 4.72 \\
$19-\mathrm{VT}$ & 4.07 & 5.02 & 4.58 & 4.14 & 5.18 \\
$12-\mathrm{VT}$ & 3.12 & 3.57 & 3.73 & 3.44 & 3.20 \\
$5-\mathrm{NH}$ & 3.45 & 3.87 & 4.03 & 3.99 & 3.67 \\
$13-\mathrm{NH}$ & 3.51 & 3.22 & 3.09 & 2.44 & 2.89 \\
$18-\mathrm{NH}$ & 3.28 & 3.88 & 3.66 & 2.86 & 3.57 \\
$3-\mathrm{NH}$ & 5.59 & 2.35 & 2.48 & $2.27^{\mathrm{b}}$ & 2.63 \\
$8-\mathrm{NH}$ & 5.06 & 4.00 & 4.14 & 4.76 & 4.40 \\
$9-\mathrm{ME}$ & $6.65^{\mathrm{a}}$ & $1.61^{\mathrm{b}}$ & $1.53^{\mathrm{b}}$ & 2.64 & $2.12^{\mathrm{b}}$ \\
$16-\mathrm{ME}$ & 4.53 & 3.94 & 3.89 & 4.45 & 4.12 \\
$15-\mathrm{ME}$ & 5.25 & 2.90 & 2.51 & 2.77 & 3.11 \\
$7-\mathrm{ME}$ & 3.14 & 3.74 & 4.37 & 5.07 & 3.46 \\
$20-\mathrm{ME}$ & 3.69 & 3.94 & 3.98 & 3.79 & 3.82 \\
$2-\mathrm{ME}$ & 3.66 & 3.07 & 3.39 & 3.73 & 2.82 \\
$10-\mathrm{ME}$ & 2.76 & 4.36 & 4.97 & 4.85 & 4.05 \\
$1-\mathrm{ME}$ & 3.21 & 5.11 & 5.07 & 4.87 & 5.02 \\
$14-\mathrm{ME}$ & 4.25 & $5.57^{\mathrm{a}}$ & 5.21 & $5.46^{\mathrm{a}}$ & $5.90^{\mathrm{a}}$ \\
\hline
\end{tabular}

Note. Scores scaled from ' 1 ' (not preferable) to '7' (highly preferable); scores denoted with ${ }^{\mathrm{a}}$ represent the high score, and scores denoted with ${ }^{\mathrm{b}}$ represent the low score in each column. sampled trail sections contain conditions that contribute to high or lowquality hiking experiences?). Table 2 notes which sections had the highest and lowest scores for each experiential element and the overall experience. Table 2 was imported into ArcMap 10.2.2 to produce map layers shown in Figs. 5-9. Fig. 5 displays section scores for level of challenge, Fig. 6 displays section scores for valuation of tread aesthetics, Fig. 7 displays section scores for the ability to maintain an ideal hiking pace, Fig. 8 displays section scores for perceived impact to the musculoskeletal system, and Fig. 9 displays section scores for overall experience.

\subsection{Level of challenge}

Section 9 received the highest score for level of challenge (6.65). Section 11 received the lowest score $(2.74)^{2}$. Sections 3 and 9 received 'highly preferable' scores and sections 10 and 11 received 'not preferable' scores (Table 2, Fig. 5).

\subsection{Valuation of tread aesthetics}

Section 14 received the highest score for tread aesthetics (5.57), and Section 9 received the lowest score (1.61). Sections 1, 11, 14, 17, and 19 received 'highly preferable' scores and sections 3 and 9 received 'not preferable' scores (Table 2, Fig. 6).

\subsection{Ability to maintain an ideal hiking pace}

Section 11 received the highest score for ability to maintain an ideal hiking pace (5.61) and similar to tread aesthetics, Section 9 received the lowest score (1.53). Sections 1, 10, 11, 14, and 21 received 'highly preferable' scores and sections 3, 9, and 15 received 'not preferable' scores (Table 2, Fig. 7).

\subsection{Perceived impact to the musculoskeletal system}

Section 14 received the highest score for perceived impact to the musculoskeletal system (5.46). Section 3 received the lowest score (2.27). Sections $4,7,11$, and 14 received 'highly preferable' scores and sections $3,9,13,15$, and 18 received 'not preferable' scores (Table 2, Fig. 8).

\subsection{Overall experience}

Section 14 received the highest score for overall experience (5.90), which is a function of high scores for aesthetics, impact, and overall experience. Section 9 received the lowest score (2.12). Sections 1, 11, 14, 17, and 19 received 'highly preferable' scores and sections 2, 3, 9, and 13 received 'not preferable' scores (Table 2, Fig. 9).

\section{Discussion}

Although researchers have tangentially explored the relationships between trail conditions and experiential elements of long-distance hiking, researchers have not investigated and mapped these relationships over 734 miles of a long-distance hiking trail. This research addressed this gap by evaluating the relationships between trail conditions and experiential elements of long-distance hiking on the northern section of the AT. The modified RSM techniques used in this study appear to provide an efficient means to compare the experiential quality of different trail sections and identify relationships between trail conditions and experiential elements of long-distance hiking. The methods and results have implications for trail managers interested in the influence of trail conditions on the hiking experience, enhancement of the hiking experience, and construction of informative maps, which are discussed in this section. In addition, this discussion addresses Research Question 3 (What are effective techniques for indexing and 


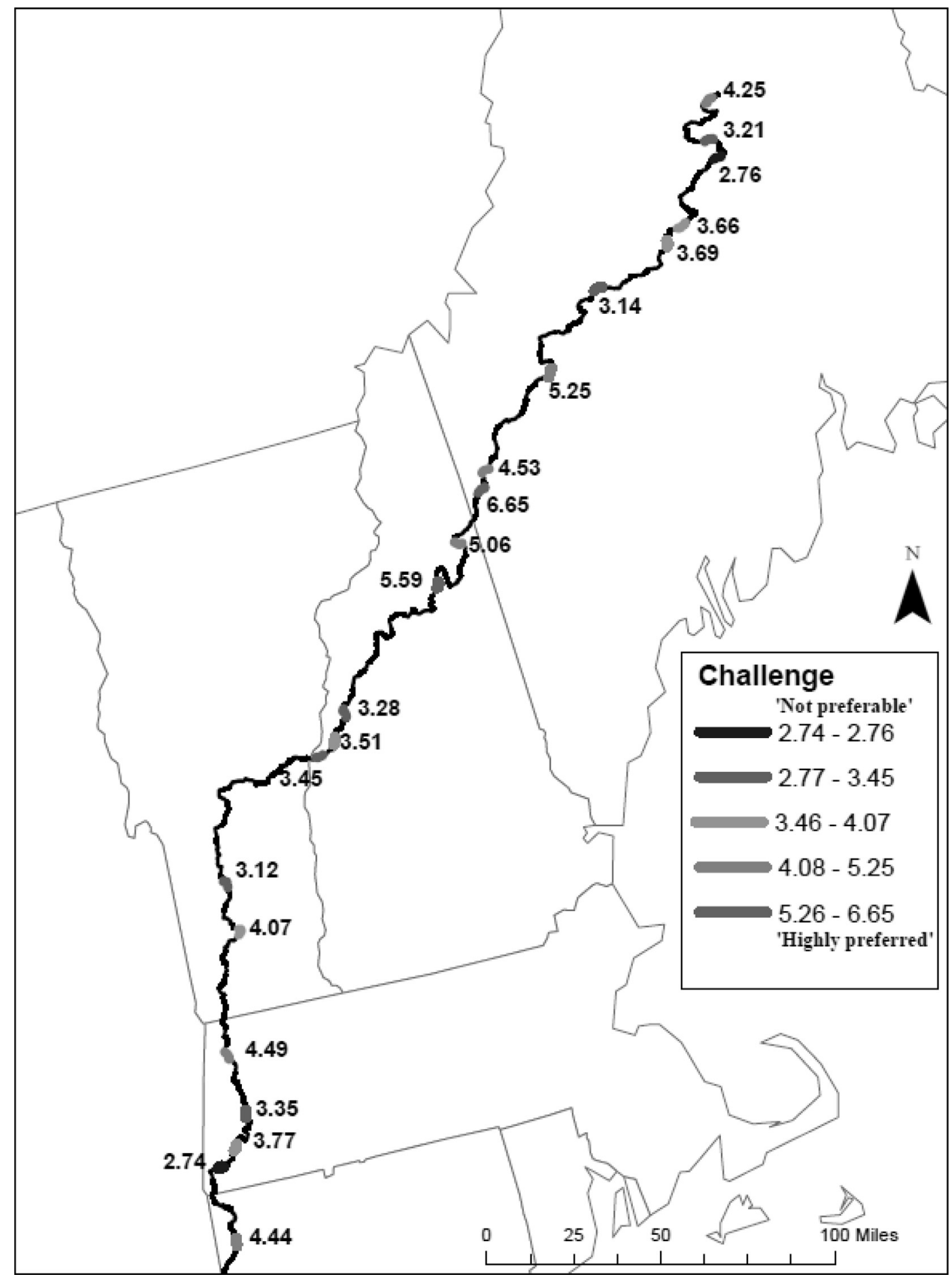

Fig. 5. Map layer for level of challenge. Scores scaled from '1' (not preferable) to '7' (highly preferable).

mapping relationships between trail conditions and experiential elements of long-distance hiking?) and Research Question 4 (How may spatially mapping the relationships between trail conditions and experiential elements of long-distance hiking inform management decisions regarding trail improvement and maintenance?).

\subsection{GIS techniques for indexing and mapping}

The methods used to index and map the social-spatial relationships in this research advanced the RSM techniques previously used by Beeco et al. (2014) and Kliskey (2000). The modified RSM methods developed in this study reveal information for restricted recreational corridors, such as a hiking trail. The two-weight method employed in this study was critical towards understanding data.

The first weight helped assign scores to trail sections for each experiential element of long-distance hiking. The resulting information after applying the weights suggests what particular type of experience is likely for each trail section considering the presence of trail conditions. For example, section 11, located in southern Massachusetts received the highest score for pace (Table 2, Fig. 7). This section is most likely a section where maintaining an ideal hiking pace is possible. Moreover, since muddiness and rugosity influence pace the most (Fig. 4), sections 


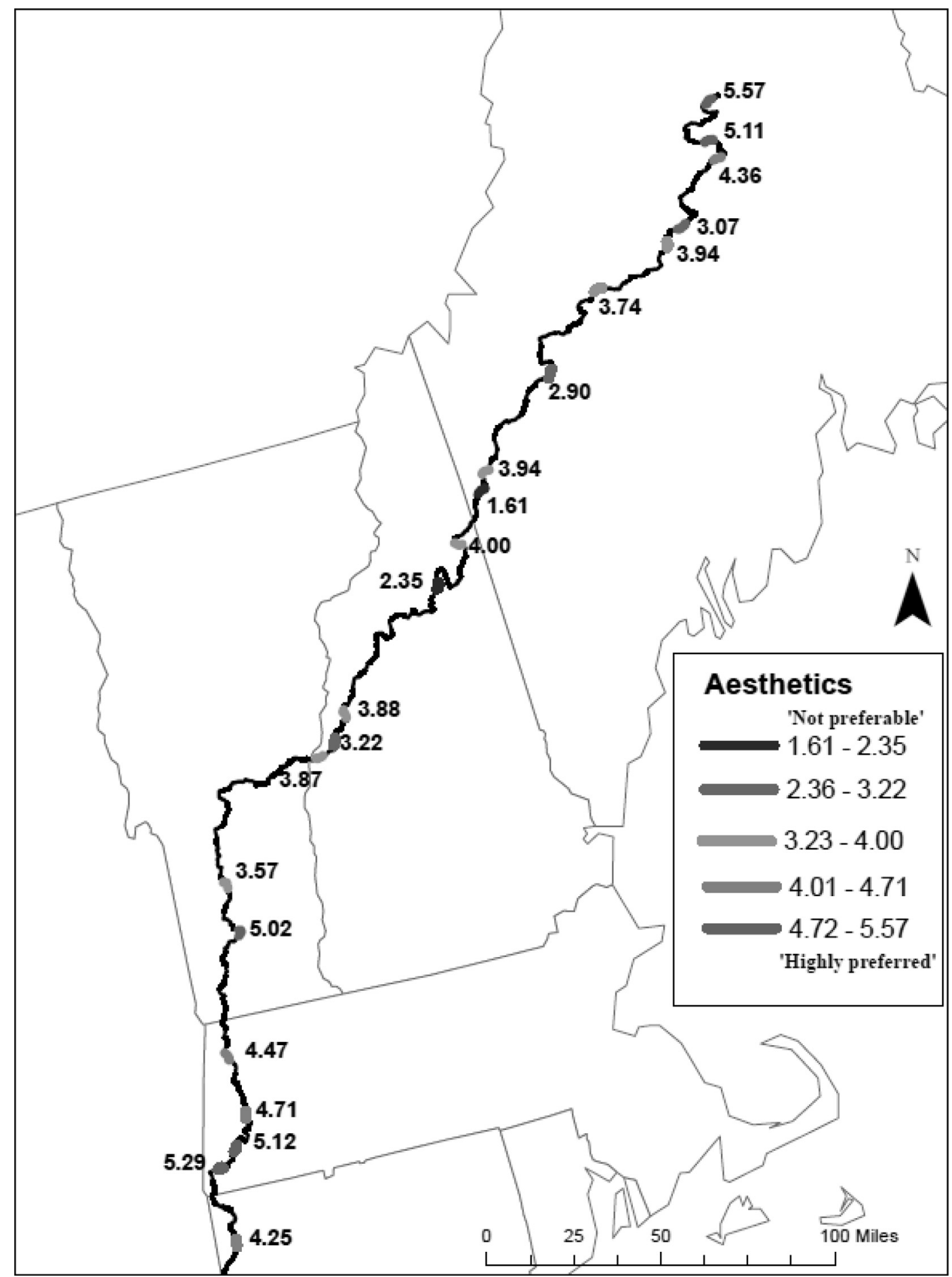

Fig. 6. Map layer for valuation of trail aesthetics. Scores scaled from ' 1 ' (not preferable) to '7' (highly preferable).

with a high pace score likely have less muddiness and rugosity. Likewise, Section 9 received the lowest score for pace. This section had higher amounts of muddiness and rugosity (Table 1). We note that seasonality can affect one of our trail condition variables, muddiness, though long-distance hikers will attest to the chronic nature of muddiness in the northeastern states, particularly in Vermont and Maine.

The second weight, which helped identify overall experience scores, reveals long-distance hikers' potential overall preference levels for a particular section. The analysis of this information helps highlight specific trail sections that may contribute to high-quality hiking experiences. For example, section 14 received the highest overall experience score, and the highest aesthetics score, and the most important experiential element to long-distance hikers was aesthetics. Since section 14 received the highest score for aesthetics, this caused this section to receive the highest score for overall experience. This relationship can further be analyzed (using Fig. 4) to see which trail conditions are most influential to aesthetics (muddiness and incision).

These modified RSM techniques may be transferable to other restricted recreational corridors once social and ecological conditions are determined and quantified with questionnaires. For example, these methods may be transferable to other trails, such as the Pacific Crest Trail (PCT), by first identifying important social and ecological 


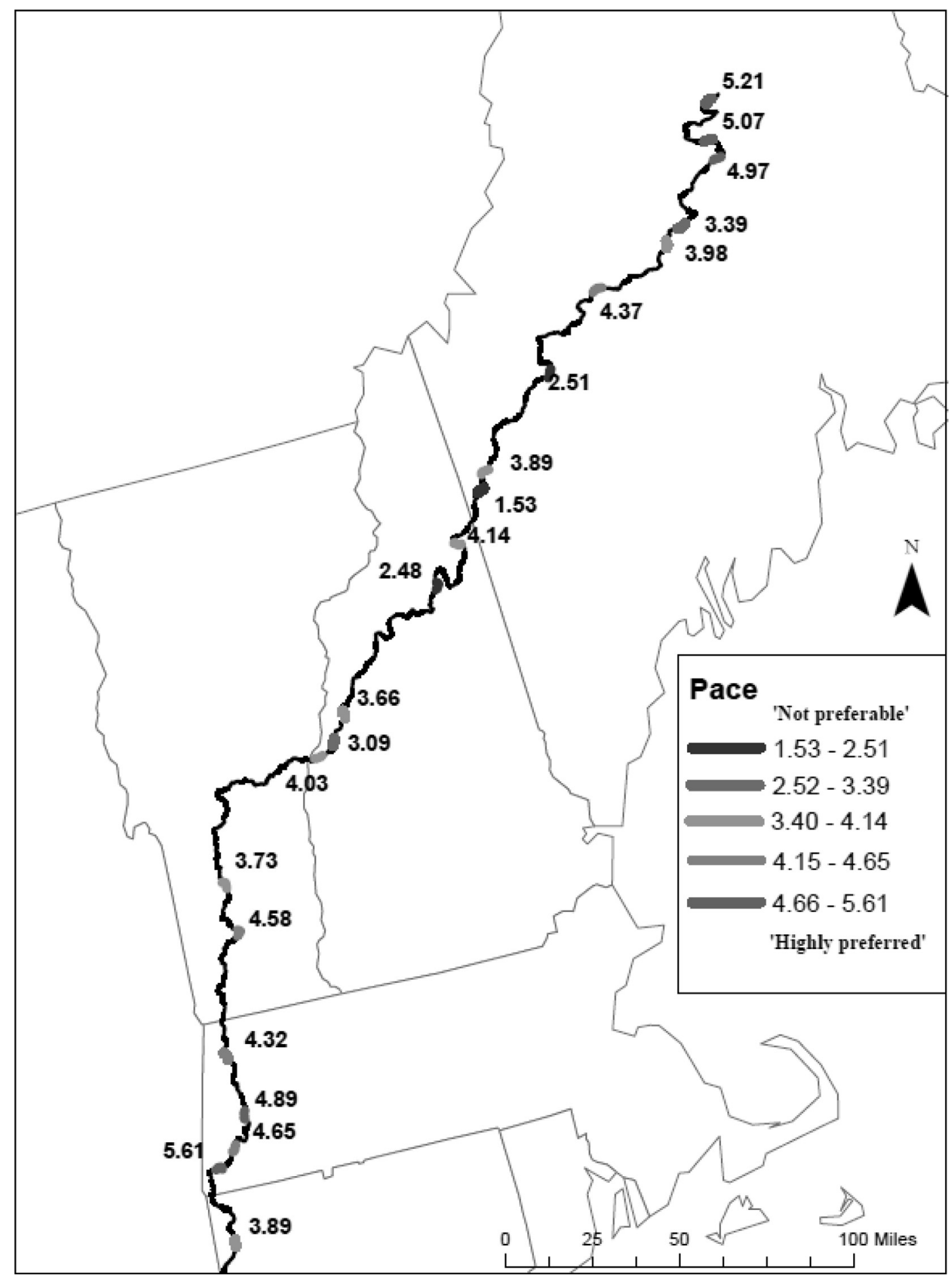

Fig. 7. Map layer for the ability to maintain an ideal hiking pace. Scores scaled from ' 1 ' (not preferable) to ' 7 ' (highly preferable).

variables, quantifying the relationships between those social and ecological variables, and measuring ecological conditions. Once mapped, this information could show the locations for scores of experiential elements and the overall experience that are unique to the PCT. In accordance the same methods are valid for international long-distance, such as the Grande Traversata delle Alpi (a 620 mile trail in the Alps) and the Kungsleden (a 270 mile trail in Sweden).

\subsection{Management implications}

Spatially mapping the relationships between trail conditions and experiential elements of long-distance hiking is important for trail sustainability. The sustainability of trails is not solely about trail design; it is also important for managers to understand how the condition of the trail influences the quality of the hiking experience. When hikers have a high-quality overall experience, they are more inclined to partake in low-impact practices towards the resource (Williams et al., 1992).

The methods used in this research provide section scores and maps that show how trail conditions influence hiking quality, and how the experience may possibly change depending on location. Resulting map layers identify experiential differences between sections. The locations of problematic experiential elements are easy to identify using the map 


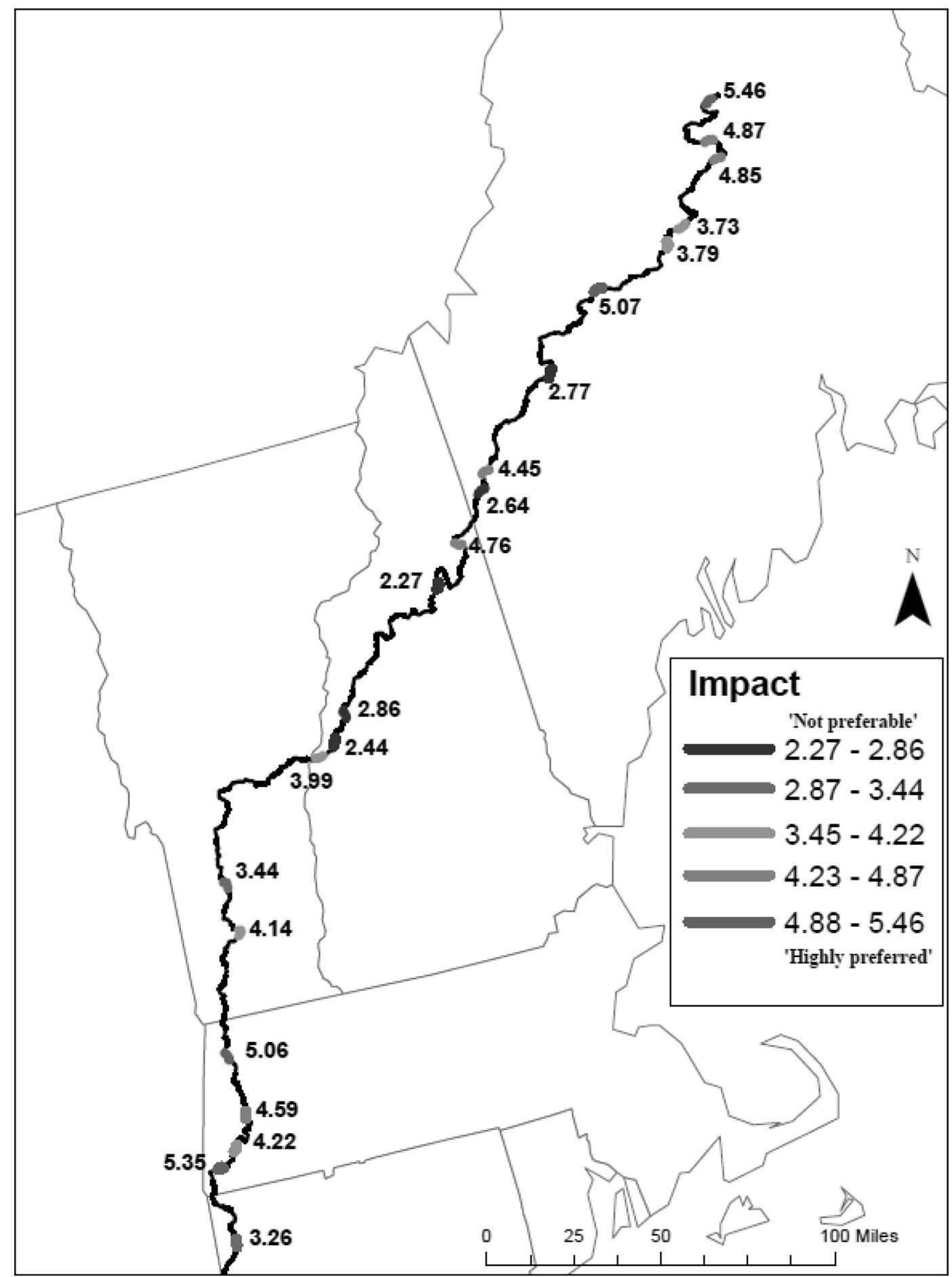

Fig. 8. Map layer for perceived impact to the musculoskeletal system. Scores scaled from '1' (not preferable) to '7' (highly preferable).

layers. It is possible to then identify problematic trail conditions in these sections. We suggest that trail managers should also consider these experiential factors when making decisions about which trail conditions should be addressed through trail relocation, reconstruction, or maintenance actions.

The researchers imported both weights into ArcMap computer software to create five map layers; one layer for each experiential element of long-distance hiking ( $\mathrm{W}_{1}$ scores), and a layer for overall experience $\left(\mathrm{W}_{2}\right.$ scores). Using the map and its associated layers, managers can quickly view and evaluate these layers to compare scores for trail sections across each experiential element and the overall experience.
Managers can analyze specific trail sections to see how experiential elements influenced the overall experience. Then using information in the results (such as Fig. 4) managers can determine a) the extent that trail conditions are present in each section; b) the level of influence of trail conditions on each experiential element; and c) the level of influence each experiential element had on the overall experience. For example, using the map and its layers, researchers and managers could initially view a section's overall experience score. Next, the manager could visually review each experiential element map layer for that trail section to analyze how that section scored for particular experiential elements to gain an understanding of which experiential outcomes are 


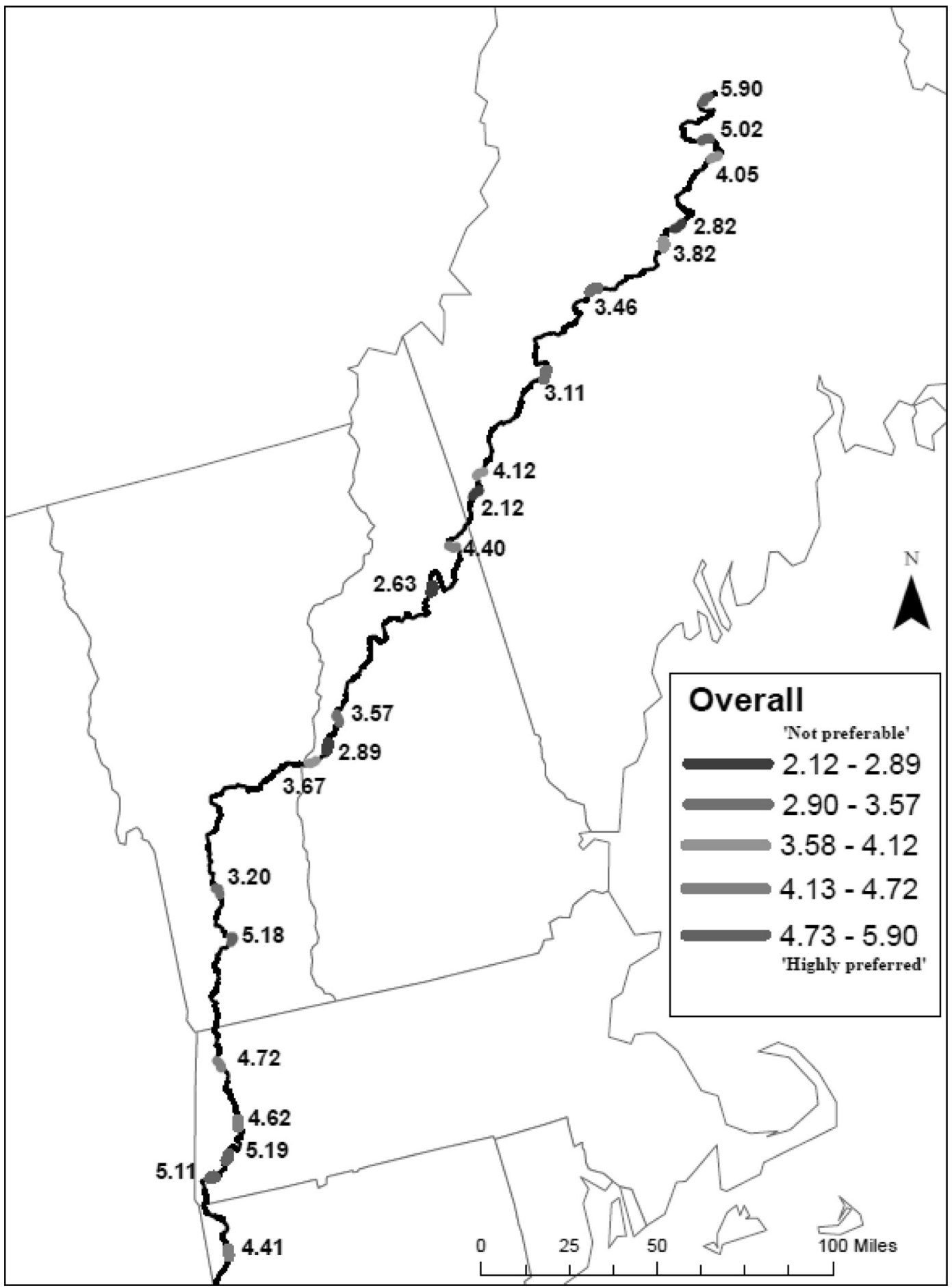

Fig. 9. Map layer for overall experience. Scores scaled from ' 1 ' (not preferable) to '7' (highly preferable).

more likely for that section. Then using information in the results (Fig. 4), managers can determine how the presence and the extent of trail conditions influenced that specific section.

Managers can use these results to design trails for specific elements of the hiking experience. For example, if managers design a trail for challenge, then the trail should contain substantial elevation gain/loss and rough terrain. Managers might choose different goals for specific trails depending on location, such as backcountry or front country settings. The information in Fig. 4 enables trail managers to design trails for particular purposes. In addition, Fig. 4 also shows evidence of which experiential elements are most important to long-distance hikers.

\subsection{Detailed discussion of sections 9 and 14}

Trail sections 9 and 14 warrant additional discussion. These two sections had extreme scores for some elements of the hiking experience and overall experience scores. Specifically, section 9, located the furthest south in Maine in Grafton Notch State Park received the lowest preferability score. Conversely, section 14, located the furthest north in Maine in Baxter State Park, received the highest score for overall preferability.

As seen in the results, the Grafton Notch State Park section received the highest score for level of challenge but received the lowest score for 
valuation of tread aesthetics, maintaining an ideal hiking pace, and overall experience. It is interesting that even though this section received the highest score for challenge, it still received the lowest overall experience score due to variable weighting. Specifically, this section's challenge score was offset by its low score for tread aesthetics, which had significantly more influence on the overall experience score. Section 9 explicitly displays the high level of importance tread aesthetics has to long-distance hikers. This section was shown to have high incision, muddiness, width, rugosity, and uphill (Table 1), which all factored into Section 9 receiving the lowest score for tread aesthetics.

Section 14 is located in northern Maine in Baxter State Park. This section received the highest score for tread aesthetics, which influenced its high overall experience score. This section had low scores for incision, muddiness, and rugosity (Table 1), which contributed to this section receiving the highest score for tread aesthetics. The findings for this section align with the regulations at Baxter State Park, which has stricter conservation rules than many of America's national parks (Baxter State Park, 2012; Irland, 1991). At Baxter State Park conservation regulations take precedence over accessibility, and it appears that management objectives and associated management practices help keep the trails in a highly preferable condition, enhancing tread aesthetics, and maintaining high-quality hiking experience. This section's high scores display Baxter State Park's priority towards the trail and associated conservation.

\subsection{Future research and limitations}

Although this research identified the relationships between trail conditions and experiential elements of long-distance hiking, limitations do exist. First, this research only analyzed 21 trail sections of the AT. Although this equates to approximately 65 miles, it is not enough information to label vast parts of the AT, such as an entire state. Additionally, the transect and segment sampling approach in this study does not allow for identification of relationships outside the sampled sections. Another limitation is that social validation of the data has not occurred. Through interviews with long-distance hikers, it is possible to validate the findings in this research. For example, researchers can interview long-distance hikers at a specific location to identify if the findings from this study align with the sentiment of the hiker. Lastly, this research only focused on 'tread aesthetics', not the visual aesthetics that surround the trail, which may include vegetation type and density, color variation, and vistas. As a result, future research should address these limitations. The research was conducted in North America and research participants were largely U.S. residents. Future research should investigate the transferability of the methods and the generalizability of results with other populations and long-distance trails outside North America.

Even though the purpose of this study was to map experiences along the AT, this could be viewed as a downside to the capabilities of RSM. It could be argued that further mapping of high-use areas, such as the Appalachian Trail, may take away from user experience, because further mapping may prevent user discovery while recreating. However, the information provided by this study is useful for planning hikes along the AT and knowing what type of experience to plan for. Even though a section may be labeled as providing a specific experience, that experience cannot be discovered until the user is on the trail and feeling the sensations and emotions that are born from hiking the trail.

\section{Conclusion}

Analyzing the relationships between trail conditions and experiential elements is an important new method for integrating the resource and experiential components of outdoor recreational experiences. This research serves as a foundational component investigating and mapping the relationships between trail conditions and experiential elements of long-distance hiking. Long-distance hiking trails are an expansive natural resource, and there must be continued evaluation of the sustainability of these massive and grand resources, and further understanding of the population hiking these trails.

\section{Acknowledgements}

The authors acknowledge and thank the U.S. National Park Service for funding the portion of this research that included the ecological field measurements (PMIS 189981). The statements, findings, conclusions, and recommendations are those of the authors and do not necessarily reflect the views of the U.S. National Park Service. Use of trade, product, or firm names is for descriptive purposes only and does not imply endorsement by the US Government.

\section{References}

Anderson, L. S., Rebholz, C. M., White, L. F., Mitchell, P., Curcio, E. P., Feldman, J. A., et al. (2009). The impact of footwear and packweight on injury and illness among long-distance hikers. Wilderness and Environmental Medicine, 20(3), 250-256.

Appalachian Trail Conservancy (2018). Thru \& section hiking. Retrieved from www. appalachiantrail.org.

Arksey, H., \& O'Malley, L. (2005). Scoping studies: Towards a methodological framework. International Journal of Social Research Methodology, 8(1), 19-32.

Ballantyne, M., \& Pickering, C. M. (2015). The impacts of trail infrastructure on vegetation and soils: Current literature and future directions. Journal of Environmental Management, 164, 53-64.

Baxter State Park (2012). Rules and regulations. Retrieved from www. baxterstateparkauthority.com.

Beeco, J. A., Hallo, J. C., \& Brownlee, M. T. (2014). GPS Visitor Tracking and Recreation Suitability Mapping: Tools for understanding and managing visitor use. Landscape and Urban Planning, 127, 136-145.

Beeco, J. A., Hallo, J. C., \& Giumetti, G. W. (2013). The importance of spatial nested data in understanding the relationship between visitor use and landscape impacts. Applied Geography, 45, 147-157.

Boulware, D. R. (2004). Gender differences among long-distance backpackers: A prospective study of women Appalachian Trail backpackers. Wilderness and Environmental Medicine, 15(3), 175-180.

Clark, V. P., \& Creswell, J. W. (2011). Designing and conducting mixed methods research. vol. 3. (pp. 93-94).

Cordell, H. K., Lewis, B., \& McDonald, B. L. (1995). Long-term outdoor recreation participation trends. In Paper presented at the Proceedings of the Fourth International Outdoor Recreation Tourism Trends Symposium. Retrieved from http://www.srs.fs. usda.gov/trends/pdf/LongTermOR95.pdf.

den Breejen, L. (2007). The experiences of long distance walking: A case study of the West Highland Way in Scotland. Tourism Management, 28(6), 1417-1427.

Dorwart, C. E., Moore, R. L., \& Leung, Y. F. (2009). Visitors' perceptions of a trail environment and effects on experiences: A model for nature-based recreation experiences. Leisure Sciences, 32(1), 33-54.

Outdoor Foundation (2017). Outdoor recreation participation topline report 2017. Retrieved from www.outdoorfoundation.org/pdf/ ResearchParticipation2017Topline.pdf.

Han, K. H., Harman, E., Frykman, P., Johnson, M., Russell, F., \& Rosenstein, M. (1992). Load Carriage. Medicine and Science in Sports and Exercise, 24(5), S129.

Hockett, K. S., Marion, J. L., \& Leung, Y. F. (2017). The efficacy of combined educational and site management actions in reducing off-trail hiking in an urban-proximate protected area. Journal of Environmental Management, 203, 17-28.

Irland, L. C. (1991). Challenges for the north Maine woods. Maine Policy Review, 1(1), $71-82$.

IVUMC (Interagency Visitor Use Management Council). (2016). Visitor Use Management Framework: A Guide to Providing Sustainable Outdoor Recreation. Interagency Visitor Use Management Council.

Jenks, G. F. (1963). Generalization in statistical mapping. Annals of the Association of American Geographers, 53(1), 15-26.

Kil, N., Stein, T. V., \& Holland, S. M. (2014). Influences of wildland-urban interface and wildland hiking areas on experiential recreation outcomes and environmental setting preferences. Landscape and Urban Planning, 127, 1-12.

Kliskey, A. D. (2000). Recreation terrain suitability mapping: a spatially explicit methodology for determining recreation potential for resource use assessment. Landscape and Urban Planning, 52(1), 33-43.

Knight, C. A., \& Caldwell, G. E. (2000). Muscular and metabolic costs of uphill backpacking: are hiking poles beneficial? Medicine and Science in Sports and Exercise, 32(12), 2093-2101.

Leung, Y. F. \& Marion, J. L. (2000). Recreation impacts and management in wilderness: A state-of-knowledge review. In Cole, D.N. and others (Eds.), Proceedings: Wilderness Science in a Time of Change; Vol 5: Wilderness ecosystems, threats, and management, pp. 23-48; May 23-27, 1999, Missoula, MT. Proceedings RMRS-P-15- vol-5. Ogden, UT: USDA Forest Service, Rocky Mountain Research Station. (http://www. wilderness.net/pubs/science1999/volume5.htm).

Lister, A. J., \& Scott, C. T. (2009). Use of space-filling curves to select sample locations in natural resource monitoring studies. Environmental Monitoring and Assessment, 149(1-4), 71-80. 
Littlefield, J., \& Siudzinski, R. A. (2012). 'Hike your own hike': Equipment and serious leisure along the Appalachian Trail. Leisure Studies, 31(4), 465-486.

Lynn, N. A., \& Brown, R. D. (2003). Effects of recreational use impacts on hiking experiences in natural areas. Landscape and Urban Planning, 64(1), 77-87.

Manning, R. (2011). Studies in outdoor recreation search and research for satisfaction (3rd ed.). Corvallis OR: Oregon State University Press.

Manning, R., \& Freimund, W. (2004). Use of visual research methods to measure standards of quality for parks and outdoor recreation. Journal of Leisure Research, 36(4), $557-579$.

Manning, R., Leung, Y. F., \& Budruk, M. (2005). Research to support management of visitor carrying capacity of Boston Harbor Islands. Northeastern Naturalist, 12(sp3), 201-220.

Marion, J. L. (2016). A Review and synthesis of recreation ecology research supporting carrying capacity and visitor use management decision-making. Journal of Forestry, 114(3), 339-351.

Marion, J. L., \& Leung, Y. F. (2001). Trail resource impacts and an examination of alternative assessment techniques. Journal of Park and Recreation Administration, 19(3), $17-37$.

Marion, J. L., Leung, Y. F., Eagleston, H., \& Burroughs, K. (2016). A review and synthesis of recreation ecology research findings on visitor impacts to wilderness and protected natural areas. Journal of Forestry, 114(3), 352-362.

Marion, J. L., Leung, Y.-F., \& Nepal, S. K. (2006). Monitoring trail conditions: New methodological considerations. The George Wright Forum, 23(2), 36-49.

Marion, J. L., \& Wimpey, J. (2017). Assessing the influence of sustainable trail design and maintenance on soil loss. Journal of Environmental Management, 189, 46-57.

McFarlane, B. L., Boxall, P. C., \& Watson, D. O. (1998). Past experience and behavioral choice among wilderness users. Journal of Leisure Research, 30, 195-213.

Monz, C. A. (2009). Climbers' attitudes toward recreation resource impacts in the Adirondack Park's Giant Mountain Wilderness. International Journal of Wilderness, 15(1), 26-33. Retrieved from http://ijw.org.

Moore, R. L., Leung, Y. F., Matisoff, C., Dorwart, C., \& Parker, A. (2012). Understanding users' perceptions of trail resource impacts and how they affect experiences: An in tegrated approach. Landscape and Urban Planning, 107(4), 343-350.

Mueser, R. (1998). Long-distance hiking: Lessons from the appalachian trail. Camden, ME: Ragged Mountain Press.

Olive, N. D., \& Marion, J. L. (2009). The influence of use-related, environmental, and managerial factors on soil loss from recreational trails. Journal of Environmental Management, 90(3), 1483-1493.
Peterson, B. (2016). Mapping the Relationships between Trail Conditions and Experiential Elements of Long-Distance Hiking. Unpublished Masters Thesis at the University of Utah.

Price, S., Blacketer, M., \& Brownlee, M. (2018). The influence of place attachment on campers' evaluations of ecological impacts due to recreation use. Journal of Outdoor Recreation and Tourism, 21, 30-38.

Ptasznik, A. (2015). Thru-hiking as Pilgrimage: Transformation, Nature, and Religion in Contemporary American Hiking Novels.

Saldaña, J. (2012). The coding manual for qualitative researchers (No. 14). Sage.

Saunders, R., Laing, J., \& Weiler, B. (2013). Personal transformation through long-distance walking. Tourist Experience and Fulfilment: Insights from Positive Psychology, 127-146.

Schreyer, R., Lime, D. W., \& Williams, D. R. (1984). Characterizing the influence of past experience on recreation behavior. Journal of Leisure Research, 16(1), 34.

Seidman, I. (2013). Interviewing as qualitative research: A guide for researchers in education and the social sciences. New York, NY: Teachers college press.

Sutherland, R. A., Bussen, J. O., Plondke, D. L., Evans, B. M., \& Ziegler, A. D. (2001) Hydrophysical degradation associated with hiking-trail use: a case study of Hawai'iloa Ridge Trail, O'ahu, Hawai'i. Land Degradation and Development, 12(1), 71-86.

Tabachnick, B. G., \& Fidell, L. S. (2007). Using multivariate statistics. Allyn \& Bacon/ Pearson Education.

Trails Days (2016). Trails Days 2016. Retrieved from www.traildays.us.

U.S. Census Bureau (2015). State and County Quickfacts: Population. Retrieved from: https://www.census.gov/quickfacts/table/PST045215/00.

Vaske, J. J. (2008). Survey research and analysis: Applications in parks, recreation and human dimensions. State College, PA: Venture Publishing.

Williams, D. R., Patterson, M. E., Roggenbuck, J. W., \& Watson, A. E. (1992). Beyond the commodity metaphor: Examining emotional and symbolic attachment to place. Leisure Sciences, 14(1), 29-46.

Wimpey, J., \& Marion, J. L. (2010). The influence of use, environmental and managerial factors on the width of recreational trails. Journal of Environmental Management, 91(10), 2028-2037.

Zealand, C. (2007). Decolonizing experiences: An ecophenomenological investigation of the lived-experience of Appalachian trail thru-hikers. A thesis presented to the University of Waterloo in fulfillment of the thesis requirement for the degree of Doctor of Philosophy in Recreation and Leisure Studies. 